\section{TEXTBOOK OF GEOCHEMISTRY}

Introduction to Geochemistry

By Konrad 13. Krauskopf. (International Series in the Earth and Planctary Sciences.) 1'p. xiii +721 . (New York: McGraw-Hill Book Co.; Maidenhead: McGrawHill Publisbing Co., 1967.) 100s.

THIS is a most useful and readable book. 'The author's aim has been to provide an introduction to geochemistry for undergraduate students who are specializing in geology, but the book has wider appeal. It shows how basic chemical concepts can be applied to the understanding of geological problems and brings the reader to the point where he can at least read contemporary geochemical literature. An American college text, its organization follows the generally accepted plan for such volumes. Thus, each chapter terminates with a useful list of books and articles suitable for wider reading, and with a pago or so of problems carefully chosen to exercise the student's grasp of the content of the chapter. As the author puts it, "ideas become part of the student's useful mental equipment only when they are reflected on, digested and manipulated and problems are a necessary goad to such activity". The chapters carry well presented tables and diagrams, but each subject is covered at a level which carefully avoids the excessive detail commonly found in research texts. Most branches of chemistry are touched on, including organic chomistry, which is needed for the discussion of organic matter in sediments and the genesis of petroleum and coal. Some chapters deal with predominantly chemical subjects such as equilibria, acids and bases, crystal structure, free energy and oxidation potentials, though the discussion is always oriented towards geological problems. The latter are covered in other chapters headed, for example, carbonate sediments, clay minerals and soils, evaporites, crystallization of magmas, organic gases, and metamorphism. Chapters of particular interest are those devoted to the distribution of the elements and historical geochemistry.

The book concludes with the collected answers to the problems and a useful appendix of data. 'There are forty pages of values for ehemical and geological data such as, for example, the radii of atoms and the abundances of elements.

G. Eghinton

\section{BARE BONES OF LIQUID METALS}

\section{Liquid Metals}

By N. H. March. (International Series of Monographs in Natural Philosophy. Vol. 15.) Pp. vii+133. (Oxford, London and Now York: Pergamon Press, 1968.) 50s.

A cumbersome title for this book might have been "An Introduction to a Unified Electronic Theory of the Properties of Metallic Liquids". 'The book could hardly have been written before because, apart from isolated papers by farsighted pioneers, the subject has grown up in the past few years. The underlying scientific problem is to find conceptual links between liquid state theory, which has dwelt much on the simple non-metals like argon, and metal theory which has been much concerned with crystals. Professor N. H. March has made valuable contributions at precisely this point and has now summarized the position in his monograph.

What does this book attempt and for whom is it written? One of its central arguments is that there exists, between ions immersed in a dense electron gas, an interaction which can be represented as the sum of effective potentials acting between all pairs of ions. This hypothesis is approached through three chapters dealing, respectively, with equations representing liquid structure, the screening of charges by electron gas, and the statistical theorios of liquids. 'This puts the author in a position to explain how effective pair potentials can be inferred from structural knowledge about liquid metals derived originally from $\mathrm{X}$-ray and neutron scattering experiments. 'This is all clearly done with help from short mathematical appendices.

It is of the essence that the electron gas density and Fermi energy play a decisive part in determining the shape and nature of the effective potential functions. Electron transport properties, so characteristic of the metallic state, aro also dominated by effective potentials felt by electrons at the Fermi energy in the presence of screened ions. Conductivity and other electron transport propertics are therefore given a longish chapter which includes elementary scattering theory.

Finally, in two chapters of greater mathematical difficulty, the author introduces two very complex and as yet not fully solved problems. One is the dynamics of atomic motion in liquids and the relevanco to it of inelastic neutron scattering, and the other is that of finding a complete description of the allowed electron states in a liquid metal.

Thus it is evident, first, that this book on liquid metals deals with theoretical physics, not with metallurgy, experimentation, or thermodynamics; second, that most of its readers will be research workers; and third, that to cover his subjects in 133 pages the author must omit much relevant matter. This is done by simplifying the mathematical exposition in a way that experimental physicists and newcomers to the field will find very agreeable, and by reducing to a minimum the description of particular substances and properties. A short introductory monograph is bound to pay this price in omissions for the odvantage of going straight to important points without beating about the bush. The author's judgment has served his readers well here except that it was a pity not to put in another admirably concise chapter on pseudopotentials-a concept so relevant to the theme.

The book can be regarded as a skeleton, not at all of the frightening kind, which will stimulate readers to cover its bare bones with material from the rapidly growing literature of the subject. Diagrams and printing are clear and the style of writing is straightforward and readable.

N. E. CUSACK

\section{IMPORTANT PROTEINS}

\section{Gamma Globulins}

Structure and Control of Biosynthesis. Edited by Johan Killander. (Proceedings of the Third Nobel Symposium held June 12-17, 1967, at Södergarn, Lidingö, in the County of Stockholm. Nobel Symposium 3.) Pp. 643. (New York and London: Interscience Publishers, a Division of John Wiley and Sons; Stockholm: Almqvist and Wiksell, 1967.) $300 s$.

MORE than fifty of the world's leading experts on the gamma globulins were brought together in Sweden to report and discuss their most recent findings and theories on this group of proteins and glycoproteins which are of paramount importance in medicine. The gamma globulins have no peers in terms of the bewildering diversity of their molecular structures and the complexity of the mechanisms that control their biosynthesis. Despite the outstanding progress that has been made in this field within recent years, largely as a result of fruitful collaboration between chemists, biochemists and clinicians, many formidable problems remain, particularly in relation to biosynthesis and its genetic control. Not only was it timely to organize this symposium, but it was particularly appropriate that the meeting was in Sweden because in many respects this was where the pioneering work was done and whero so many of the methodological advances in medical biochemistry had their origin. The advances resulting 